\title{
4L Lymph Node Involvement in Left-Sided Lung Cancer: Unique or Not?
}

\author{
Dirk K.M. De Ruysscher, MAASTRO Clinic, Maastricht, the Netherlands \\ Herbert Decaluwé, University Hospitals Leuven, Leuven, Belgium
}

See accompanying article on page 2935

In the article that accompanies this editorial, Wang and colleagues ${ }^{1}$ report on the prognostic impact of dissecting the station 4L mediastinal lymph node (LN) in left-sided lung cancer. Using propensity score weighting, two retrospective patient groups who received surgery between 2005 and 2009 were compared: one with $4 \mathrm{~L}$ dissection $(\mathrm{n}=139)$ and one without $(\mathrm{n}=518)$. No chemotherapy was given, and staging with $\left[{ }^{18} \mathrm{~F}\right]$ fluorodeoxyglucose (FDG) positron emission tomography/computed tomography (PET/CT) scanning, brain imaging, or invasive mediastinal staging (if indicated) was not systematically performed. Therefore, the results cannot be extrapolated to centers where these procedures are common practice. The overall rate of involvement of station $4 \mathrm{~L}$ was nearly $21 \%$, and the 5 -year overall survival (OS) and disease-free survival were significantly superior for the group that had a $4 \mathrm{~L}$ LN dissection (disease-free survival: $54.8 \% v 42.7 \%$; $P=.04$; OS: $58.9 \% \vee 47.2 \% ; P=.02$ ). The conclusion is that $4 \mathrm{~L}$ involvement is not rare, especially when station $10 \mathrm{~L}$ is involved, and that the station $4 \mathrm{~L}$ LN should be systematically dissected at the time of surgery. These findings are intuitively attractive.

It should be stressed that the definition of what exactly station $4 \mathrm{~L}$ is differs according to surgical or nonsurgical literature. ${ }^{2}$ Wang et $\mathrm{al}^{1}$ used the surgical definition in their study. Complete resection of station $4 \mathrm{~L}$ may be technically challenging because of its anatomic relation with the aortic arch, the thoracic duct, and the recurrent nerve. Operative complications are therefore more frequent, and station $4 \mathrm{~L}$ may not be resected adequately. ${ }^{3}$ Nevertheless, when radical surgery is being considered, a systematic $\mathrm{LN}$ dissection is frequently advocated. ${ }^{3}$ Given the technical challenges of performing a station $4 \mathrm{~L}$ dissection, some have questioned whether the rate of incomplete resection is higher for $4 \mathrm{~L}$ dissection compared with other LN stations. An indirect way to assess the rate of incomplete resections is to look at the patterns of recurrence after surgery for stage III non-small-cell lung cancer. If the rate of incomplete resection of station $4 \mathrm{~L}$ is higher than the rates for other LN stations, it can reasonably be expected that the local recurrence rate will be higher as well. However, this has not been observed. ${ }^{4-6}$ The majority of local recurrences after surgery for left-sided lung cancer do not occur in station $4 \mathrm{~L}$; instead, they occur in stations $4 \mathrm{R}$ and 7 . Station $4 \mathrm{~L}$ can be resected completely with video-assisted mediastinal lymphadenectomy, which results in optimal staging and local treatment at the same time in many patients. ${ }^{7}$ The complete surgical removal of station $4 \mathrm{~L}$, as recommended in most guidelines, is therefore feasible and appropriate. ${ }^{8}$ From a surgical point of view, $4 \mathrm{~L}$ should therefore be regarded as an $\mathrm{LN}$ station that should be resected in left-sided lung cancers with a success rate comparable to that of other LN stations.

The question of whether removal of station $4 \mathrm{~L}$ will lead to a survival gain is more difficult to prove. Indeed, randomized phase III trials failed to show that systematic versus lobe-specific nodal dissection had any impact on OS, although more patients were upstaged to N2 disease and therefore had an indication for adjuvant chemotherapy. ${ }^{9,10}$ The findings in the Wang et al ${ }^{1}$ study, that surgical removal of station $4 \mathrm{~L}$ might improve OS, should therefore be viewed as hypothesis generating only. As the authors note, their study is retrospective with significant known imbalances in the prognostic factors between the group treated with $4 \mathrm{~L}$ dissection and the other group. Propensity techniques are an attempt to deal with the imbalance of confounders, but they are by no means as strong as randomization. ${ }^{11}$ The reason why the majority of patients did not undergo a dissection of $4 \mathrm{~L}$ in the same time period is unknown and adds to bias, which is difficult to correct for. In addition, pathologic TNM staging was used as confounder for the propensity weighting instead of clinical TNM, adding possible bias and suggesting incomplete preoperative staging. Conversely, not removing $4 \mathrm{~L}$ in a left-sided cancer would not comply with current recommendations and would qualify the resection as being incomplete. ${ }^{12}$ In these cases, postoperative radiotherapy is recommended, although improvements in local tumor control rates have been reported without a proven benefit on OS. ${ }^{13,14}$ Obviously, this is the case only when $4 \mathrm{~L}$ is not FDG-avid or not enlarged on CT scan. In the case of macroscopic involvement, an attempt should be made to obtain pathology from station $4 \mathrm{~L}$, and postoperative chemoradiotherapy is recommended in the case of involvement and incomplete resection.

The article by Wang et $\mathrm{al}^{1}$ thus provides us with useful data that underscore the recommendation to dissect station $4 \mathrm{~L}$, although the effect on OS remains unproven. In the case of nonremoval of station 4L that is not involved on FDG-PET/CT, and in the absence of $10 \mathrm{~L}$ involvement, postoperative radiotherapy may be omitted. If $10 \mathrm{~L}$ is involved, irradiating $4 \mathrm{~L}$ is of uncertain value. Clear involvement of $4 \mathrm{~L}$ qualifies for postoperative chemotherapy and radiotherapy.

\section{AUTHORS' DISCLOSURES OF POTENTIAL CONFLICTS OF INTEREST}

Disclosures provided by the authors are available with this article at jco.org. 
AUTHOR CONTRIBUTIONS

Manuscript writing: All authors

Final approval of manuscript: All authors

\section{REFERENCES}

1. Wang $Y-N$, Yao $S$, Wang $C-L$, et al: Clinical significance of $4 \mathrm{~L}$ lymph node dissection in left lung cancer. J Clin Oncol 36:2935-2942, 2018

2. Tournoy KG, Annema JT, Krasnik M, et al: Endoscopic and endobronchial ultrasonography according to the proposed lymph node map definition in the seventh edition of the tumor, node, metastasis classification for lung cancer. J Thorac Oncol 4:1576-1584, 2009

3. Trujillo-Reyes JC, Martínez-Téllez E, Rami-Porta R, et al: Combination video-assisted mediastinoscopic lymphadenectomy and transcervical thoracoscopy. Multimed Man Cardiothorac Surg 10.1510/mmcts.2018.004, 2018

4. Feng W, Fu XL, Cai XW, et al: Patterns of local-regional failure in completely resected stage IIIA(N2) non-small cell lung cancer cases: Implications for postoperative radiation therapy clinical target volume design. Int J Radiat Oncol Biol Phys 88:1100-1107, 2014

5. Billiet C, De Ruysscher D, Peeters S, et al: Patterns of locoregional relapses in patients with contemporarily staged stage III-N2 NSCLC treated with induction chemotherapy and resection: Implications for postoperative radiotherapy target volumes. J Thorac Oncol 11:1538-1549, 2016

6. Kępka L, Bujko K, Bujko M, et al: Target volume for postoperative radiotherapy in non-small cell lung cancer: Results from a prospective trial. Radiother Oncol 108:61-65, 2013
7. Decaluwé $H$, Dooms C, D'Journo XB, et al: Mediastinal staging by videomediastinoscopy in clinical $\mathrm{N} 1$ non-small cell lung cancer: $\mathrm{A}$ prospective multicentre study. Eur Respir J 50 https://doi.org/10.1183/13993003.01493-2017

8. Postmus PE, Kerr KM, Oudkerk M, et al: Early and locally advanced nonsmall-cell lung cancer (NSCLC): ESMO Clinical Practice Guidelines for diagnosis, treatment and follow-up. Ann Oncol 28:iv1-iv21, 2017

9. Mokhles $S$, Macbeth $F$, Treasure $T$, et al: Systematic lymphadenectomy versus sampling of ipsilateral mediastinal lymph-nodes during lobectomy for nonsmall-cell lung cancer: A systematic review of randomized trials and a metaanalysis. Eur J Cardiothorac Surg 51:1149-1156, 2017

10. Darling GE, Allen MS, Decker PA, et al: Randomized trial of mediastinal lymph node sampling versus complete lymphadenectomy during pulmonary resection in the patient with No or N1 (less than hilar) non-small cell carcinoma: Results of the American College of Surgery Oncology Group Z0030 Trial. J Thorac Cardiovasc Surg 141:662-670, 2011

11. Kim DH, Pieper $C F$, Ahmed $A$, et al: Use and interpretation of propensity scores in aging research: A guide for clinical researchers. J Am Geriatr Soc 64:2065-2073, 2016

12. Rami-Porta $R$, Wittekind $C$, Goldstraw $P$ : Complete resection in lung cancer surgery: Proposed definition. Lung Cancer 49:25-33, 2005

13. Billiet $C$, Peeters $S$, Decaluwé $H$, et al: Postoperative radiotherapy for lung cancer: Is it worth the controversy? Cancer Treat Rev 51:10-18, 2016

14. Francis S, Orton A, Stoddard G, et al: Sequencing of postoperative radiotherapy and chemotherapy for locally advanced or incompletely resected nonsmall-cell lung cancer. J Clin Oncol 36:333-341, 2018

DOI: https://doi.org/10.1200/JCO.2018.79.3299; published at jco.org on August 27, 2018.

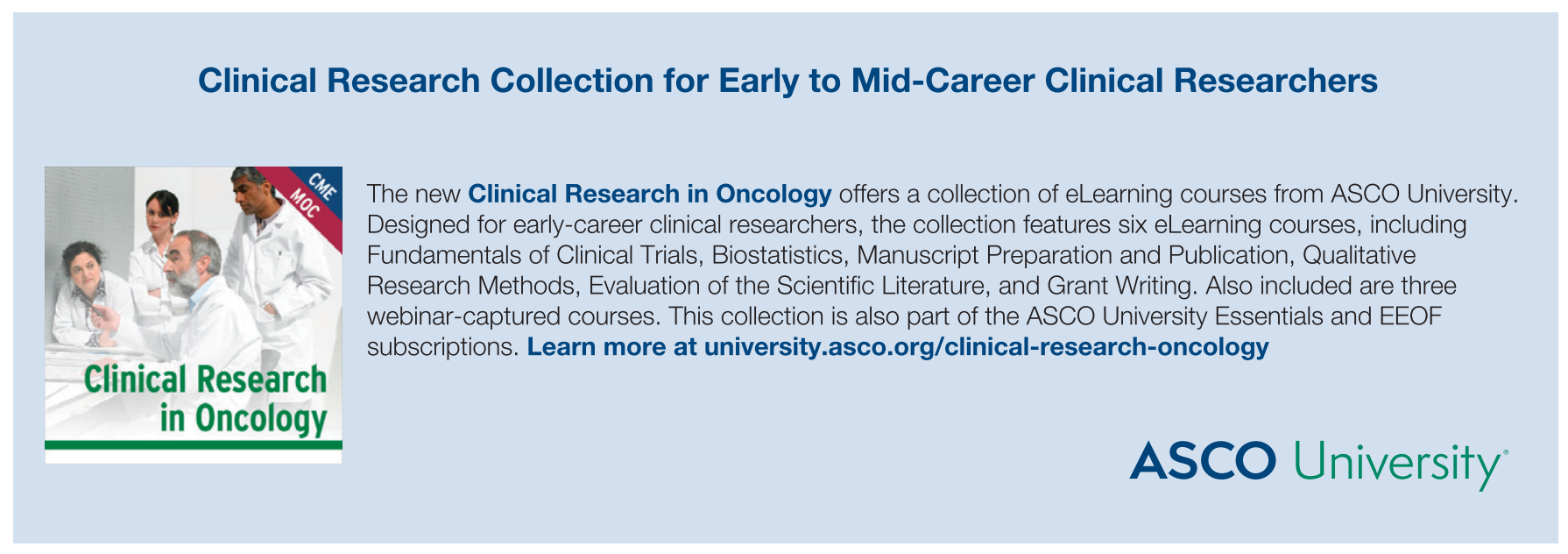




\section{AUTHORS' DISCLOSURES OF POTENTIAL CONFLICTS OF INTEREST}

4L Lymph Node Involvement in Left-Sided Lung Cancer: Unique or Not?

The following represents disclosure information provided by authors of this manuscript. All relationships are considered compensated. Relationships are self-held unless noted. I = Immediate Family Member, Inst = My Institution. Relationships may not relate to the subject matter of this manuscript. For more information about ASCO's conflict of interest policy, please refer to www.asco.org/rwc or ascopubs.org/jco/site/ifc.

Dirk K.M. De Ruysscher

Consulting or Advisory Role: Bristol-Myers Squibb (Inst), AstraZeneca (Inst), Merck Serono (Inst), Celgene (Inst), Genentech (Inst)

Research Funding: Bristol-Myers Squibb (Inst), Boehringer Ingelheim (Inst)

\section{Herbert Decaluwé}

No relationship to disclose 